\title{
DIVERS@!
}

\section{USOS DO TEMPO E TECNOLOGIAS NO ESPAÇO DOMÉSTICO: UM OLHAR DE GÊNERO}

\author{
USES OF TIME AND \\ TECHNOLOGICAL ARTIFACTS IN THE \\ HOUSEHOLD SPACE: A GENDER \\ $L O O K$
}

\section{Nadia Terezinha Covolan ${ }^{7}$ Marilia Gomes de Carvalho ${ }^{8}$}

Resumo: Apresentam-se os resultados parciais e quantitativos, de pesquisa sobre os usos do tempo em relação às tecnologias presentes no espaço doméstico. Cotejam-se teorias com dados encontrados a partir da aplicação de questionário, respondido por 24 homens e 101 mulheres, pesquisadores/as de gênero de diferentes universidades do Brasil. Apontam-se permanências e transformações nos usos do tempo e tecnologias: os eletrodomésticos facilitam o trabalho doméstico sem necessariamente reduzir o tempo gasto nestas tarefas, que permanecem feminilizadas; as tecnologias da informação e comunicação (TIC) estão imbricando os tempos de trabalho profissional, doméstico e de lazer, em uma simultaneidade de atividades realizadas no lar. Nesse contexto, considera-se o impacto da categoria gênero nos estudos da ciência, tecnologia e sociedade (CTS).

\footnotetext{
${ }^{7}$ Pós doutoranda em Tecnologia pelo Programa de Pós Graduação em Tecnologia (PPGTE) da Universidade Tecnológica Federal do Paraná (UTFPR); Doutora em Ciências Humanas (UFSC), Mestre em Tecnologia; docente da UFPR (litoral); pesquisadora sobre Gênero e Estudos de Ciência, Tecnologia e Sociedade (CTS).

${ }^{8}$ Pós-doutora pela Université de Technologie de Compiègne - França; Doutora em Antropologia Social - USP; Pesquisadora do Núcleo de Pesquisas sobre Gênero e Tecnologia - PPGTE/UTFPR; realiza estudos sobre gênero, ciência e tecnologia; gênero e educação, cultura e diversidade cultural; cultura e gênero.
}

Palavras Chaves: Tempo, Tecnologia, Gênero

Abstract: Here is the partial and quantitative results of research on the uses of time in relation to technological artifacts in the household space. We compare theories with data found from the questionnaire, answered by 24 men and 101 women, researchers/s gender of different universities in Brazil. We point permanence and change in time and technology uses: appliances facilitate the housework without necessarily reducing the time spent on these tasks, which remain feminized; information and communication technologies (ICT) are present in the household space, the professional working hours, domestic and leisure, in a simultaneity of activities in the home. We consider the impact of gender category in the studies of science, technology and society (STS).

Keywords: Time, Technology, Gender

\section{Introdução}

Este artigo é parte de uma pesquisa iniciada em março de 2014, cujas bases estão assentadas na assertiva de que o tempo tem significado pessoal, social e político, portanto, não é neutro. Assim como o tempo, as tecnologias são construções sociais, apropriadas, significadas e usadas de modos diferentes pelas pessoas. As influências das tecnologias presentes nos ambientes dos trabalhos formais, informais e domésticos, sobre o modo como homens e mulheres vivenciam o cotidiano, abarcam amplos fatores sociais, porém, considera-se que no espaço doméstico as regras de gênero se 


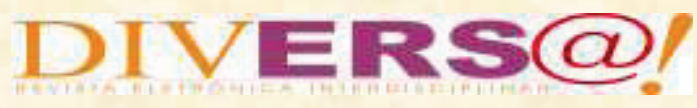

destacam e marcam fortemente os usos do tempo.

Neste artigo, interpelam-se as categorias tempo, espaço, tecnologias e gênero, para investigar permanências e transformações nos usos do tempo e tecnologias domésticas para homens e mulheres. Objetiva-se, com a apresentação desses resultados parciais da pesquisa, contribuir para a inserção da categoria gênero na agenda dos estudos CTS (Ciência, Tecnologia e Sociedade).

\section{Considerações Teóricas}

O tempo é um recurso de poder, e seu uso difere de acordo com o gênero, a configuração familiar, a camada social, a raça/etnia, a geração, entre outras dimensões que se interpelam. Diante dessa problemática, gênero é considerado o principal articulador das regras sociais, em todas as instancias.

As conquistas femininas das ultimas décadas, especialmente a entrada de grande número de mulheres no mercado de trabalho, não ocasionaram alterações significativas na realização do trabalho doméstico e de cuidados, a elas tradicionalmente delegados. Estudos demonstram que as mulheres permanecem como as responsáveis pelos encargos do lar, do cuidado dos/das filhos/as, idosos/as, doentes e também de adultos/as não dependentes, somando tarefas em várias jornadas de trabalho. Hildete Pereira de
Melo et all, tendo por base os procedimentos usuais de bens ou serviços não mensurados por estatísticas econômicas, conclui que no Brasil, os afazeres domésticos correspondem, em média, a 11,2\% dos PIBs no período 20012005. (MELO, CONSIDERA, SABBAT0, 2007)

Este estudo vai de encontro aos aportes de Cristina Carrasco, para quem o modelo capitalista vigente exige um tempo que as mulheres não têm, dado que estão atendendo a produção e a reprodução da vida, no lar. As profundas desigualdades entre mulheres e homens em todos os aspectos da vida fazem com que as atividades tradicionalmente delegadas para as mulheres, suas formas de atuar e pensar, suas relações, ações e corpos sejam desvalorizados. Trabalhadoras de tempo integral, as mulheres não conseguem tempo para cuidarem de si e se desenvolverem enquanto pessoas que tem desejos e valores próprios; geralmente renunciam ao tempo e espaço próprio para seu desenvolvimento pessoal, em beneficio dos outros e para satisfazer as necessidades materiais e afetivas dos membros da família. A economia monetária depende da não monetária, ou seja, a sociedade depende do trabalho doméstico realizado dentro da família, por ser esse o âmbito dos afetos que, sob a ótica da economia, não têm preço no mercado. Dessa forma, a autora situa o bem-estar humano - a 


\section{DIVERS@!}

sustentabilidade da vida, como objetivo social e político. Assim, para mensurar os usos do tempo é necessário recuperar o valor do feminino, tornando visível os aspectos subjetivos do cuidado e seu recorte de sexo/gênero (CARRASCO, 2012).

Por sua vez, Amartya Sen reconhece o trabalho doméstico como contributo forte para a prosperidade, porém, por não ser remunerado nem dividido igualmente entre homens e mulheres, considera que o emprego fora de casa para as mulheres, é mais visível e importante; ele diz que este constitui de fato, um fator educativo porque expõe a mulher ao mundo, aumentando a eficácia de sua agência. Afirma ainda, que a imagem da mulher como heroína relegada ao sacrifício pelo lar e pela família, não a beneficiou em nada e nem às sociedades, e a superação da teoria do sacrifício pode dar lugar à do êxito feminino, se houver apoio social. (SEN, 2010)

Pesquisas em nível global demonstram que a educação e a renda aferida pelas mulheres, interferem diretamente na sobrevivência delas próprias, na diminuição do número de filhos e da mortalidade materna e infantil, na diminuição dos conflitos armados e da violência em geral e na conservação dos recursos naturais, dentre outros fatores. Esse impacto da educação/renda feminina na sociedade, não ocorre quando os homens são educados e recebem salários (SEN, 2010).

Carrasco não se detém no fato do lar ser freqüentemente o local da violência e do perigo assim como Sen não enfatiza as limitações impostas às mulheres trabalhadoras, apesar desses aportes serem fundamentais para a abordagem da questão de gênero nas suas variadas expressões.

A precarização do trabalho feminino no mercado tem sido tema de variados estudos. A visão da mulher trabalhadora como mãe/filha/esposa, geralmente se contrapõe à do trabalhador, com ou sem vínculos, considerado disponível e com capacidade superior para o trabalho. No entanto, o trabalho formal das mulheres, mesmo com o reforço da discriminação e da desigualdade, mesmo sendo mal pago, diz Helena Hirata, traz maior visibilidade ao trabalho doméstico; ou seja, pela ausência da mulher no lar, surge com maior clareza a necessidade e a importância do trabalho dentro de casa, invisível e não remunerado. (HIRATA, 2010)

No lar os espaços de trabalhos formais e/ou domésticos estão imbricados com artefatos tecnológicos e são mediados pela informatização e virtualidade, que influenciam e demandam tempos e tarefas relacionadas. Estas dependem em seus usos e representações, da pessoa haver nascido homem ou mulher. As concepções de linearidade e neutralidade do 
tempo/espaço, no que tange aos seus usos nos diferentes lugares, podem obscurecer formas diversificadas de desigualdade social, especialmente as relacionadas às questões de gênero. O tempo no espaço público, de domínio masculino, com suas tecnologias específicas, é mensurável, positivado e considerado universal em oposição ao tempo privado do ambiente doméstico, não menos permeado de tecnologias, porém invisibilizado e desconsiderado, tendo sido tradicionalmente delegado ao universo feminino.

Nesse estudo, enfocamos os usos do tempo em relação aos artefatos tecnológicos do lar, mediados pelas assimetrias de poder de gênero.

\section{A pesquisa}

Para medir os usos do tempo, a exemplo de outros países, o Brasil tem privilegiado a metodologia de elaboração de diários, que registra o tempo dedicado a cada atividade que as pessoas, geralmente casais, realizam num dia. Esta pesquisa difere dessa abordagem, pois enfoca o tempo utilizado em relação às tecnologias (linha branca e marrom) presentes no lar, por pesquisadoras e pesquisadores de gênero de diferentes universidades do país, mediante postagem de questionário em plataforma virtual.
O ambiente doméstico é o lócus onde se mesclam as dimensões do trabalho acadêmico, das relações pessoais, de satisfações de necessidades vitais, incluindo lazer e descanso. Esse ambiente está permeado por variados artefatos tecnológicos, que influenciam os usos dos tempos dos homens e das mulheres. Há dois grupos de artefatos tecnológicos relacionados a seu uso no lar: as tecnologias de linha branca e as de linha marrom: Dentre as de linha branca foram considerados: fogão, geladeira, forno elétrico; microondas; freezer; máquinas de lavar roupa; máquinas de lavar louça; aspirador de pó e produtos de limpeza. Dentre os de linha marrom consideramos: televisão, DVD, computador, CD players, internet, celular, tablet, e aparelhos de som.

A elaboração do questionário partiu das seguintes questões norteadoras: a) como se estabelecem os usos do tempo que envolvem artefatos tecnológicos no espaço doméstico, para esse grupo de especialistas? b) Em que medida o fato de pesquisar gênero tem influenciado os seus usos do tempo no lar?

A partir das indagações acima, elaboramos um questionário a ser enviado para pesquisadoras/es de núcleos ou grupos de estudos de gênero em diferentes universidades do Brasil. As 14 questões versaram sobre o perfil das/os respondentes; quanto tempo se ocupam na execução de trabalhos domésticos; a 


\section{DIVERSQ!}

relação entre o uso do tempo e o uso de eletrodomésticos no lar; o uso do tempo e o uso de TICs (Tecnologias de Informação e Comunicação) no ambiente doméstico; os usos do tempo em relação aos artefatos tecnológicos presentes no lar, relativos a estudos, cuidado de si, lazer, contatos sociais, busca de informações.

O questionário,

utilizando o software Q Qualtrics, foi enviado para cerca de 200 pesquisadoras/es. As questões foram respondidas por 24 homens, 101 mulheres, 1 outro, num total de 126 pesquisadoras/es, a grande maioria morando no sul do país. Tendo em vista que apenas 1 respondente assinalou com relação ao gênero a alternativa 'outro', consideramos este, um dado não representativo para a presente análise, mas sim para outra abordagem futura. Dessa forma, foram considerados 125 respondentes, sendo 24 homens e 101 mulheres.

\section{O perfil das e dos respondentes}

Sobre o perfil do grupo selecionado, destaca-se a grande diferença no número de respondentes masculino e feminino, conforme pode-se observar no Gráfico 1 . O resultado corrobora a formação dos grupos e núcleos de gênero na Academia, compostos expressivamente por maioria de mulheres, nos quais a participação dos homens se apresenta por cerca de pouco mais que $10 \%$, de acordo com a observação empírica.

Gráfico 1 - Número de respondentes quanto ao gênero

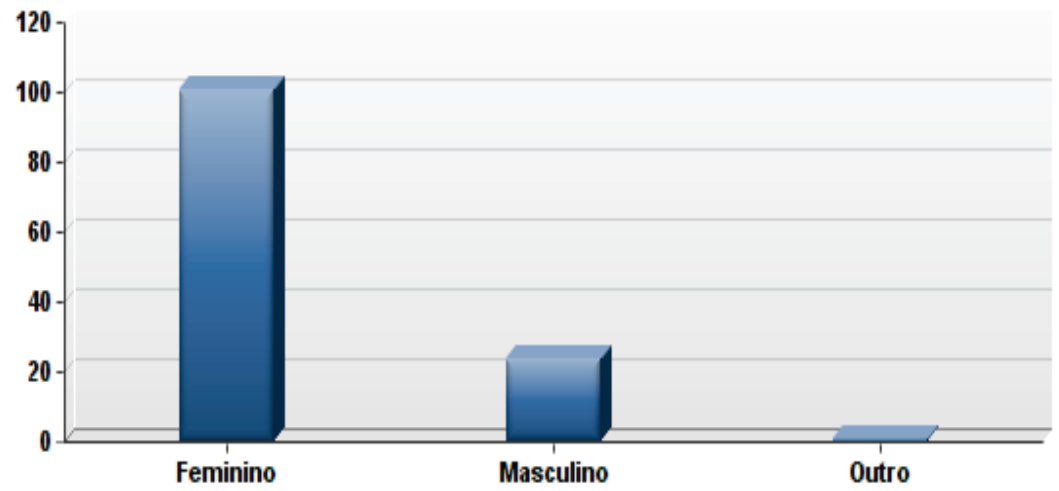

\section{Dados da pesquisa}

Quanto à faixa etária, $46 \%$ dos respondentes, ou seja, 11 homens têm menos de 30 anos; 38\% deles, isto é, 9 homens estão entre 30 a 45 anos, demonstrando nessa amostragem, que os estudos de gênero e masculinidades têm interessado a homens mais jovens. As 101 mulheres respondentes, por sua vez, estão representadas em todas as idades: $26 \%$ tem até 30 anos, $38 \%$ de 30 a 45 anos, $25 \%$ de 45 a 60 anos, e $12 \%$ tem mais de 60 anos. Notadamente, esse tema tem interessado mais a mulheres do que a homens. Outrossim, infere-se que as pesquisadoras 


\section{DIVERS@!}

com mais de 60 anos, provavelmente são pioneiras nas pesquisas de gênero, coordenadoras de pesquisas nas pós graduações, que permanecem incentivando as/os mais jovens.

Destaca-se que $56 \%$ das/os respondentes, são da área das Ciências Humanas e Sociais. As áreas da Engenharia (5\%), da Saúde (4\%), Letras e Artes (8\%) e Agronomia (8\%), estão representadas nessa amostragem em menor número, porém não menos significativo. Esses dados revelam que a maioria das/os pesquisadoras/es em núcleos de pesquisa sobre gênero pertencem à área das Ciências Humanas e Sociais, em razão dos temas abordados por estas ciências, porém, revelam também que, por ser uma questão interdisciplinar, os estudos de gênero estão pouco a pouco adentrando outras áreas do conhecimento.

A maioria das mulheres, $43 \%$, mora com companheiros ou cônjuges; $63 \%$ dos homens moram sozinhos, com companheiro ou com amigos, o que corresponde ao viés da faixa etária mais jovem dos pesquisadores. Em que pese variadas respostas a essa questão, as pessoas moram em sua maioria com parentes (mãe, filho/a, pai, sogra, cônjuge), revelando assim, que as relações familiares permanecem como referência importante para a formação da unidade de residência.

\section{Resultados Preliminares}

\subsubsection{Os usos do tempo no trabalho doméstico}

$\mathrm{Na}$ constelação doméstica, 44 mulheres (44\%) e 11 dos homens (46\%) afirmaram que são as/os que mais ocupam tempo na execução das tarefas domésticas. Nesse contexto, em que pese a proporcionalidade entre os/as pesquisadas/os, o fato de 24 mulheres e 4 homens citarem que obtém ajuda de empregadas domésticas, demonstra que o trabalho doméstico permanece feminilizado, apesar da participação masculina. Os dados encontrados estão relacionados a mudanças na esfera doméstica, como a escolaridade, o rendimento familiar e a região do país, corroborando com pesquisas oficiais no país, como apontamos a seguir.

Na PNAD 2005, por exemplo, consta que no Brasil, 109,2 milhões de pessoas de 10 anos ou mais de idade declararam exercer atividades domésticas, sendo essas, 71,5 milhões de mulheres. A população de 25 a 49 anos de idade realiza mais afazeres domésticos, porém, considerando a população de cada grupo etário, são as pessoas de 50 a 59 anos que despendem maior parte do seu tempo nessas atividades, ou seja, 24,3 horas semanais. As desigualdades de gênero são visíveis, pois $51,1 \%$ dos homens realizam afazeres domésticos em relação a 90,6\% das 


\section{DIVERS@!}

mulheres. Para os homens, a maior jornada em afazeres domésticos ocorre se eles vivem em arranjos familiares com cônjuge e sem de filhos/as, que é de 11 horas semanais (PNAD, 2005).

Estes dados expressam que a maior responsabilidade pelos filhos é da mulher. Nesse contexto, a menor participação dos homens nos afazeres domésticos ocorre no nordeste, $46,7 \%$, enquanto que no Sul se evidencia a maior taxa (62\%). Uma possível explicação estaria em que no nordeste os aspectos culturais de masculinidade são mais fortes. De acordo com a jornada média em afazeres domésticos, se verifica maior intensidade deste trabalho para a população com até 4 anos de estudo (21,8 horas semanais). É na população com 12 anos ou mais de estudo que se verifica o menor tempo dedicado aos afazeres domésticos, sejam homens ou mulheres. Isso ocorre possivelmente porque a escolaridade tem correlação com a renda, permitindo com que tais atividades possam ser contratadas. Para as mulheres com esse nível de escolaridade, a jornada com afazeres domésticos é cerca 5 horas/ semana menor do que a jornada observada para as mulheres menos escolarizadas. $\mathrm{Na}$ população masculina, quem mais realiza afazeres domésticos são os mais escolarizados (54\%), enquanto que para as mulheres ocorre o inverso. São as mulheres mais escolarizadas que menos contribuem para o trabalho doméstico, inclusive são as que dedicam menos tempo com essas tarefas. (SOARES e SABÓIA, 2007)

Este estudo abarca homens e mulheres intelectuais, no caso homens especialmente sensíveis para a questão de gênero, cujos resultados coincidem com os dados citados acima.

\subsection{Os usos do tempo em relação às tecnologias da linha branca}

Ruth Schwartz Cowan (1983), pesquisando a história das tecnologias domésticas nos lares americanos, afirma que a sua introdução transformou a rotina doméstica, mas não diminuiu a quantidade desse trabalho. Conforme a autora, houve uma reorganização dos processos de trabalho, uma vez que alguns foram eliminados e outros modificaram a forma como eram realizados. De acordo com Cowan, tecnologias do início do século XX como água encanada, ferro elétrico, luz elétrica, facilitaram o trabalho doméstico para as mulheres de elite e classe média, porém, essas tecnologias coincidem com transformações no mundo do trabalho, que levaram à diminuição de criadas que realizavam este trabalho. Além disso, outras necessidades foram criadas, tais como o maior cuidado com a higiene do ambiente doméstico, decorrente de maior conhecimento sobre a proliferação de germes e bactérias causadores de doenças. Portanto, mesmo com as tecnologias modernas, o trabalho doméstico 


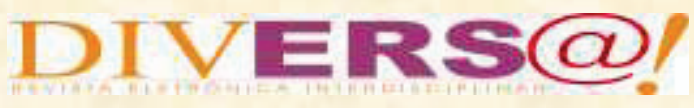

permaneceu exigindo, tanto ou mais tempo das mulheres que o realizavam (COWAN, 1983).

As variadas tecnologias para executar tarefas domésticas, durante $\mathrm{o}$ século XX popularizaram-se com a promessa de poupar tempo e energia, principalmente das donas de casa. Máquina de lavar roupa, freezer, geladeira, fogão, aspirador, detergente e outros artefatos são tão comuns, a ponto de não se poder pensar em uma casa sem esses. No entanto, estudos demonstraram que as tecnologias domésticas não garantem a "redução do tempo dedicado ao trabalho doméstico, ou um maior equilíbrio na partilha deste trabalho entre homens e mulher" (SCHOUTEN et all, 2012, p. 33). Das pesquisas com esse enfoque, este relatório destaca o realizado pela norte americana Joann Vanek (1974), sobre como as tecnologias facilitadoras das tarefas domésticas produzem um tempo de 'sobra', utilizado pelas mães nos cuidados de filhos/as e parentes. Outras/os autoras/es argumentam que o equipamento doméstico mais sofisticado pode ter um 'efeito perverso' na partilha de tarefas entre homens e mulheres, ou seja, quando os homens consideram uma tarefa doméstica fácil, eximem-se com mais facilidade de executar tal trabalho.(SCHOUTEN et all, 2012)

A assertiva acima dialoga com os achados dessa pesquisa sobre a contribuição dos eletrodomésticos na execução de tarefas no lar: 10 homens e 55 mulheres responderam que esses facilitam os processos, sem necessariamente reduzir o tempo das atividades. No entanto, 8 homens e 37 mulheres responderam que essas tecnologias reduzem o tempo do trabalho doméstico, o que revela que esta questão necessita de pesquisas mais aprofundadas.

Segundo o PNAD, em 2001, 33,64\% dos domicílios particulares permanentes no Brasil possuíam máquina de lavar roupas. Em 2011, esse número subiu para 51\%. De acordo com um levantamento do IPEA (Instituto de Pesquisa Econômica Aplicada), feito em 2009, as mulheres que têm a lavadora de roupas gastam duas horas por semana a menos nos afazeres da casa se comparadas àquelas que não têm o equipamento (IPEA, 2009)

Em entrevista dada a Karina Serenzuela em 06 de março de 2014, Maria Rosa Lombardi diz: "não tenho dúvidas que a tecnologia alivia o trabalho, mas o que essa mulher faz com essas horas antes ocupadas pelos afazeres do lar?" Para a autora, o mercado absorve esse 'tempo livre', dando a impressão de que o tempo gasto com o trabalho remunerado invade cada vez mais o tempo familiar e de lazer. Sobre essa questão, Helena Hirata, na mesma entrevista discorda que as horas ocupadas com as tarefas do lar tenham 
diminuído com as tecnologias. Nesse sentido, refere que o tempo poupado pelos eletrodomésticos permanece sendo usado nos afazeres do lar e no cuidado com familiares e filhos/as: "Acredito que as ações públicas sociais, como o acesso à creche ajuda bem mais a mulher a trabalhar fora do que o emprego da tecnologia dentro de casa" (SEREZUELLA, 2014)

Pode-se acrescentar que creches, associadas às tecnologias domésticas, certamente são elementos fundamentais para o trabalho feminino fora de casa. Por outro lado, é importante ressaltar que mudanças na divisão sexual do trabalho no lar, com a maior participação masculina nas atividades domésticas e do cuidado são imprescindíveis para diminuir a desigualdade de gênero na família. Não restam dúvidas que as tecnologias aliviam as atividades domésticas, porém, criam outras necessidades. A ciência popularizada induz a novos procedimentos relacionados aos cuidados das crianças e da casa, que demandam tempo e estudo. Tecnologias aparecem relacionadas à higiene, alimentação, psicologia, nutrição, jardinagem, decoração, vestuário, medicamentos, exercícios, dentre outras. Isso ocasiona uma intensa cobrança das mulheres, para dar conta desses variados saberes, sem os quais não seria possível ser uma boa mãe, uma boa mulher, uma boa esposa, uma boa filha, uma boa profissional, enfim, uma mulher eficiente, ou seja, uma mulher 'de verdade' 9 .

\section{3 - O uso das tecnologias da linha marrom no lar}

Sobre o uso de computador (desktop ou noteboock), e/ou tablet e/ou celular e internet em casa, 78 mulheres e 13 homens responderam que utilizam esses artefatos no lar, o maior tempo, para obter informações relacionadas ao trabalho profissional e acadêmico. Quanto a esse dado, ressaltamos que nossa pesquisa enfoca um grupo de pesquisadoras/es universitárias/os, que invariavelmente trazem para casa as tarefas do trabalho acadêmico, como é costume junto a essa população.

Nos dados colhidos em questionário, chama a atenção a imbricação do trabalho formal, informal e doméstico no âmbito do lar, relacionado ao uso das tecnologias. Uma das expressões escritas revela uma situação cada vez mais comum: "é minha ferramenta de trabalho, fonte de lazer e contato com amigos. Tudo junto e misturado." Esta frase, encontrada em um dos questionários, revela que as TICs

\footnotetext{
${ }^{9}$ É importante ressaltar aqui a questão da classe social. A situação descrita acima está mais presente entre mulheres das camadas médias ou da elite. Nos grupos populares, nem sempre é possível às mulheres darem conta de tantas cobranças, tendo em vista as desigualdades na escolaridade e nas condições materiais de vida, incluindo a falta de tempo para todos os afazeres.
} 
(Tecnologias da Informação e corpo' (ex: saúde, estética, Comunicação) vêm favorecendo o condicionamento físico, etc), não foi desaparecimento da rígida separação entre as atividades do trabalho profissional fora de casa e o trabalho doméstico. São tecnologias que possibilitam às pessoas realizarem parte de seu trabalho profissional em casa, ao mesmo tempo em que realizam as suas atividades do lar. Assim, hoje é possível uma ou um profissional realizar um trabalho acadêmico, por exemplo, enquanto cuida da roupa na máquina, do assado no forno e do telefonema da mãe doente. Essa situação revela a sobrecarga que essa pessoa assume, o que explica muitos problemas de saúde, especialmente o stress característico no universo pesquisado.

Dentre 101 mulheres respondentes, 20 assinalaram o uso das TICs para atividades de lazer, por exemplo, assistir filmes, ouvir musica e ter contato com amigos/as nas redes sociais; e 9 homens dos 24 respondentes. Sobre a maior parte do tempo dedicado ao lazer, 5 mulheres assinalaram a questão, enquanto 2 homens a marcaram. Considerando a proporção de respondentes, esse resultado revela que as mulheres usufruem menos tempo que os homens para lazer no espaço doméstico.

Outro dado significativo foi a não pontuação do uso das tecnologias do lar para a alternativa referente ao cuidado de si. Nesse contexto, a opção 'cuidar do assinalada nem por homens nem por mulheres. Encontra-se aqui mais uma evidencia da sobrecarga de trabalho anteriormente comentada, associada à falta do lazer necessário para a reposição do equilíbrio físico e emocional.

Sobre o tempo de uso do computador e/ou tablet e/ou celular com internet, em casa: 12 homens e 48 mulheres utilizam de 3 a 6 horas por dia; 7 homens e 15 mulheres utilizam de 7 a 10 horas por dia; 1 homem e 30 mulheres utilizam até 2 horas por dia. A amostra revela que proporcionalmente as mulheres usam as TICs por menos tempo que os homens no lar. No entanto, revela também que tanto homens como mulheres utilizam de modo regular e constante, essas tecnologias no ambiente doméstico.

Para muitas mulheres em torno dos 30 anos, casadas e/ou com filhos/as, as tarefas domésticas são intensificadas e se somam às do trabalho formal. Por outro lado, geralmente os homens nessa faixa de idade, podem dedicar-se ao mercado de trabalho, sem a preocupação do trabalho doméstico. A atuação das mulheres no mercado formal de trabalho impõe agilidade no desempenho das atividades domésticas. Como fica o tempo pessoal, para cuidado de si, do lazer, da sexualidade, dos estudos? 


\section{DIVERS@!}

Nas alternativas sobre o uso da maior parte do tempo da pessoa no espaço doméstico, há uma mesma seqüência de alternativas para homens e para mulheres: em primeiro lugar, 12 homens e 51 mulheres, utilizam a maior parte do seu tempo em atividades acadêmicas; em segundo lugar, utilizam computador, e em terceiro, o tempo é utilizado para a realização de trabalhos domésticos.

Finalmente, sobre a importância dos estudos de gênero para a conquista de maior igualdade entre homens e mulheres na divisão do trabalho no lar (questão ainda em análise), os resultados parciais revelaram que cerca de $67 \%$ dos pesquisadores e $78 \%$ das pesquisadoras de gênero concordam que seus estudos contribuíram para modificar a dinâmica de suas atividades no âmbito de seu próprio lar, no sentido de uma distribuição mais igualitária de tarefas entre os sexos/gêneros.

\section{Conclusões}

Este trabalho teve como objetivo investigar os usos do tempo e das tecnologias no âmbito doméstico entre pesquisadoras e pesquisadores de gênero de diferentes universidades do Brasil. Nos resultados parciais, identificaram-se permanências de padrões tradicionais nas atividades domésticas que mantém desigualdades de gênero, porém pode-se dizer que transformações importantes estão ocorrendo.

Uma das mudanças mais significativas, que está diretamente relacionada ao uso de artefatos tecnológicos, tanto os eletrodomésticos quanto as TICs, foi o fato de que os limites entre o tempo de trabalho profissional, de trabalho doméstico e de lazer estão se tornando cada vez mais imbricados. Os dados da pesquisa revelam que está ocorrendo uma simultaneidade de atividades realizadas no espaço doméstico. O uso do tempo no lar já não é mais dedicado apenas para o trabalho doméstico e/ou do cuidado. Os eletrodomésticos permitem realizar este trabalho mais rapidamente, poupando tempo, enquanto as TICs possibilitam realizar o trabalho profissional em casa. Isto está tornando os limites entre os domínios público/privado/doméstico cada vez mais nebulosos.

Esse fenômeno leva a relativizar a assertiva de que inovações tecnológicas ocorrem sempre, para facilitar a vida humana. $\mathrm{O}$ mais rápido acesso à comunicação e informação proporcionadas pelas TICs, podem trazer uma sobrecarga de trabalho, especialmente para as mulheres, que não se 'desligam' do trabalho profissional quando o encerram no final do dia, mesmo quando realizam seus afazeres de casa ou quando poderiam 
usufruir um tempo para o lazer e o cuidado de si.

A vida social é marcada por mudanças e permanências. Alguns valores, costumes e hábitos são mais renitentes às mudanças do que outros. Constata-se que houve pouca mudança na divisão sexual do trabalho doméstico e das atividades de cuidado. As mulheres continuam usando muito mais de seu tempo para a realização destes trabalhos do que os homens, como tradicionalmente vêm sendo a elas delegados, em que pesem todas as tecnologias domésticas.

Quanto a este aspecto é possível considerar que os valores da maternidade e da boa esposa vigentes na sociedade, estão associados à realização das atividades do cuidado, incluindo o trabalho doméstico, fazendo com que sejam vividas como manifestação de amor à família. Deste ponto de vista, alterar este modelo é mais difícil. Também esta divisão sexual de trabalho é reforçada cotidianamente pela publicidade de artefatos tecnológicos para o lar, que permanecem sendo divulgados como produtos destinados às mulheres.

Essa investigação está possibilitando outras informações que ainda estão sendo processadas. O grupo enfocado é restrito, porém, mediante seu olhar peculiarmente sensível ao gênero, podem-se aferir dados para embasar novas pesquisas, mais amplas e com outros públicos.

\section{Referências}

CARRASCO, Cristina. Estatísticas sob suspeita: proposta de novos indicadores com base na experiência das mulheres. Tradução José Valenzuela Perez. São Paulo: SOF Sempreviva Organização Feminista, 2012.

COWAN, Ruth Schwartz. More work for mother: the ironies of household technology from the open hearth to the microwave. New York: Basic Books, 1983.

HIRATA, Helena. Tendências Recentes da Precarização social e do Trabalho:Brasil, França, Japão. CADERNOCRH, Salvador, v. 24, n. spe 01, p. 13-20, 2011

MELO, Hildete P. CONSIDERA, Claudio M. SABBATO, Alberto. Os afazeres domésticos contam. Economia e Sociedade. Campinas, v. 16, n. 3 (31), p. 435-454, dez. 2007.

SCHOUTEN, Maria Johanna. Tempo e Tecnologia: uma abordagem de género para o contexto português. Covilhã, 2012.

SEN, Amartya. Desenvolvimento como liberdade, São Paulo, Companhia das Letras, 2010.

SEREZUELLA, Karine. Os eletrodomésticos deram mais tempo livre à mulher? Especialistas analisam, 2014. http://www.ipea.gov.br

SOARES, Cristiane, SABOIA, Ana L. Trabalho e afazeres domésticos: um estudo com base nos dados da Pesquisa Nacional por Amostra de Domicílios de 2001 e 2005, RJ: 2007. http://www.ibge.gov.br 